Article

\title{
Intraocular Inflammation Control and Changes in Retinal and Choroidal Architecture in Refractory Non-Infectious Uveitis Patients after Adalimumab Therapy
}

\author{
Vittorio Pirani ${ }^{1}$, Paolo Pelliccioni ${ }^{1}, *$ (), Serena De Turris ${ }^{1}$, Alessandro Rosati ${ }^{1}$, \\ Alessandro Franceschi ${ }^{1}$ (D), Pierangelo Pasanisi ${ }^{1}$, Rosaria Gesuita ${ }^{2}$, Michele Nicolai ${ }^{1}$ and \\ Cesare Mariotti ${ }^{1}$ \\ 1 Eye Clinic, Polytechnic University of Marche, via Conca 61, 60126 Ancona, Italy; \\ piranivittorio@virgilio.it (V.P.); serena_deturris@hotmail.it (S.D.T.); alessandro.rosati8@gmail.com (A.R.); \\ a.franceschi.md@gmail.com (A.F.); pierangelo.pasanisi@ospedaliriuniti.marche.it (P.P.); \\ michele.nicolai@ospedaliriuniti.marche.it (M.N.); mariottiocul@gmail.com (C.M.) \\ 2 Centre of Epidemiology and Biostatistics, Polytechnic University of Marche, via Conca 61, 60126 Ancona, \\ Italy; r.gesuita@univpm.it \\ * Correspondence: paopel@hotmail.it
}

Received: 18 December 2019; Accepted: 11 February 2020; Published: 13 February 2020

\begin{abstract}
Background: Non-infectious uveitis represents a leading cause of visual impairment, and inflammation control represents a major priority in tackling visual acuity loss due to complications such as macular edema; different immunomodulatory drugs are currently being used, including anti-TNF-alpha Adalimumab. Methods: This was a monocentric observational study of 18 eyes of 18 patients with non-infectious uveitis treated with Adalimumab. The primary endpoint was the control of ocular inflammation. The secondary endpoints included the study of macular and choroidal thickness and architecture, visual acuity, changes in other treatments, and adverse effects. Results: Ocular inflammation was controlled at 12 months for $83.3 \%$ of patients. Central macular thickness improved from a median of $229.75 \mu \mathrm{m}$ at baseline to $213 \mu \mathrm{m}$ at 12 months, while choroidal thickness decreased by $11.54 \%$ at the end of the follow-up. A reduction of vasculitis on fluorescein angiography and of hyperreflective spots on optical coherence tomography was noted. Visual acuity also improved from $0.51(\log M A R)$ before treatment to 0.24 at more than 12 months ( $p=0.01)$. A total of $11.1 \%$ of patients experienced side effects. Conclusion: Our study confirms the efficacy of adalimumab for the control of ocular inflammation, visual acuity preservation, and for corticosteroid sparing.
\end{abstract}

Keywords: Adalimumab; anti-TNF- $\alpha$; non-infectious uveitis; refractory uveitis; inflammatory macular edema; macular thickness; choroidal thickness; retinal vasculitis; retinal hyperreflective spots

\section{Introduction}

Non-infectious uveitis (NIU) is reported to have affected more than 298.000 adults (estimated prevalence 121/100.000) and more than 21.000 children (estimated prevalence 29/100.000) in the United States in 2015 [1,2]. Audrey et al. [3] reported that NIU represents the fifth leading cause of visual impairment and it is accountable for about $10 \%-15 \%$ of legal blindness in middle-aged patients, predominantly between 20 and 50 years of age in developed countries [4-6] and up to $25 \%$ in the developing world [7-9]. 
Macular Edema (ME) represents the most common cause of sight loss among uveitis patients, because of its influence on "central vision" $[7,10,11]$, and it has been found to be more common in those forms of uveitis that affect the more posterior structures of the eye [12]. Rothova et al. [13] showed that $45 \%$ of patients with posterior uveitis presented visual impairment, and $28 \%$ of them also had ME $[4,13]$. Uveitic ME is defined as a thickening of the macular region due to an inflammatory breakdown of the outer and/or inner blood-retina barrier (BRB) with consequent leaking from perifoveal capillaries and the accumulation of intracellular and extracellular fluid [14]. BRB breakdown may result from a strong inflammatory context and be due to many factors including vascular endothelium growth factor (VEGF), pro-inflammatory cytokines such as TNF- $\alpha$, IL-1, TGF-beta, angiotensin II, IL-6, and IL-8, and metalloproteinases secreted by leukocytes $[4,15,16]$.

NIU diagnosis is usually made based on clinical evaluation, blood testing, and multimodal imaging. Optical coherence tomography (OCT) has become the gold standard tool for the diagnosis of $\mathrm{ME}$, since it is non-invasive, reproducible, rapid, and sensitive. It may accurately quantify macular and choroidal thickness and show fluid accumulation, the state of photoreceptor outer/inner segment line, hyperreflective dots, epiretinal membranes, and vitreomacular tractions [4]. Retinal fluorescein angiography (FA) is helpful for showing dye diffusion and dye pooling in the macular area, detecting ischaemic zones, and screening for associated vasculitis. Indocyanine green angiography (ICGA) is used to identify the inflammation of choroidal stroma and vessels $[17,18]$. A further diagnostic tool is fundus autofluorescence (FAF), which supplies insight into the metabolic state of the photoreceptors/retinal pigment epithelium complex, examining the presence of lipofuscin $[17,19]$.

The treatment of NIU with inflammation control represents a major priority in tackling visual impairment due to complications such as ME [7,20], and it is the focus of our study. Corticosteroids have been traditionally used as first-line treatment [21] and are delivered by various routes, including systemic, local (periocular injections), and intraocular, with the limitation that they are associated with many side effects $[22,23]$. The second-line class of drugs includes non-corticosteroid immunomodulatory agents such as T-cell inhibitors (cyclosporine, tacrolimus), antimetabolites (azathioprine, mycophenolate mofetil, methotrexate), and alkylating agents (cyclophosphamide) [24-27]. In refractory cases, biologic agents such as interferons, immunoglobulins, and anti-Tumor Necrosis Factors have all been tried with varying degrees of success [28-30].

Adalimumab (Humira ${ }^{\circledR}$; AbbVie Inc., North Chicago, IL, USA) received, in June 2016, Food and Drug Administration approval to treat adults with non-infectious intermediate, posterior, and panuveitis [3]. Adalimumab is a recombinant human IgG1 monoclonal antibody that targets human Tumor Necrosis Factor- $\alpha$ (TNF- $\alpha$ ) [31]. The recent VISUAL trials [32-34] provided level 1 evidence supporting the clinical efficacy of this molecule in reducing the frequency of inflammation relapse for uveitis patients with a wide range of uveitic diagnoses [30,32,35].

In this study, we report our experience with the use of anti TNF- $\alpha$ (adalimumab) in patients affected by recalcitrant NIU by analyzing retinal and choroidal findings obtained by means of multimodal imaging after the administration of biologic systemic therapy.

\section{Experimental Section}

\subsection{Study Population}

This retrospective monocentric observational study was conducted at the Eye Clinic, Polytechnic University of Marche, Ancona, Italy. Thirty-five eyes of 18 patients with non-infectious uveitis treated with Adalimumab injections were enrolled from January 2017 to October 2019. The procedures of this study were in accordance with the Declaration of Helsinki and its later amendments. Written informed consent was obtained from all individual participants included in this paper, and the local Institutional Review Board (IRB) was informed (in accordance with the Italian Law in case of observational studies). All patients had uncontrolled uveitis at the time of the first anti-TNF- $\alpha$ administration. Uveitis was classified according to Standardization of Uveitis Nomenclature (SUN) criteria [36]: all cases presented 
chronic intermediate, posterior or panuveitis (Table 1). Most patients had been treated unsuccessfully with other immunosuppressive agents before the first Adalimumab injection.

Table 1. Clinical data of enrolled patients.

\begin{tabular}{|c|c|c|c|c|c|c|}
\hline \multirow{2}{*}{ Patient No. } & \multirow{2}{*}{ Etiology } & \multirow{2}{*}{ Classification } & \multirow{2}{*}{ Uni/Bilateral } & \multirow{2}{*}{ Previous Treatment } & \multicolumn{2}{|c|}{ Current Treatments } \\
\hline & & & & & $\begin{array}{l}\text { Drugs in } \\
\text { Addition to } \\
\text { Anti-TNF }\end{array}$ & $\begin{array}{l}\text { Daily Steroid } \\
\text { Dose }>10 \mathrm{mg}\end{array}$ \\
\hline 1 & $\begin{array}{l}\text { Psoriatic } \\
\text { arthritis }\end{array}$ & Posterior & Bilateral & Etanercept & No & no \\
\hline 2 & $\begin{array}{l}\text { Psoriatic } \\
\text { arthritis }\end{array}$ & Panuveitis & Bilateral & Prednisone, MTX & MTX & no \\
\hline 3 & Behçet & Posterior & Unilateral & Prednisone, AZA & Prednisone & no \\
\hline 4 & Behçet & Posterior & Bilateral & Prednisone, AZA & Prednisone & yes \\
\hline 5 & Behçet & Posterior & Bilateral & Prednisone, AZA & Prednisone & yes \\
\hline 6 & Behçet & Posterior & Bilateral & Prednisone, AZA & Prednisone & yes \\
\hline 7 & Behçet & Panuveitis & Bilateral & Prednisone, AZA & AZA & no \\
\hline 8 & Behçet & Panuveitis & Bilateral & Prednisone, MTX & $\begin{array}{l}\text { Prednisone, } \\
\text { MTX }\end{array}$ & yes \\
\hline 9 & Behçet & Panuveitis & Bilateral & Prednisone, AZA & Prednisone & no \\
\hline 10 & $\begin{array}{c}\text { Behçet }+ \\
\text { Rheumatoid } \\
\text { arthritis } \\
\text { Behcet }+\end{array}$ & Panuveitis & Bilateral & Prednisone, AZA & AZA & no \\
\hline 11 & $\begin{array}{l}\text { Multifocal } \\
\text { choroiditis }\end{array}$ & Posterior & Bilateral & Prednisone, AZA & AZA & no \\
\hline 12 & Behçet, SLE & Posterior & Bilateral & $\begin{array}{c}\text { AZA, } \\
\text { Hydroxychloroquine }\end{array}$ & AZA & no \\
\hline 13 & $\begin{array}{l}\text { Birdshot } \\
\text { Choroiditis }\end{array}$ & Panuveitis & Bilateral & Prednisone, AZA & AZA & no \\
\hline 14 & Panuveitis & Panuveitis & Bilateral & Prednisone & Prednisone & no \\
\hline 15 & Pars Planitis & Intermediate & Bilateral & Prednisone, CSA & CSA & no \\
\hline 16 & Pars Planitis & Intermediate & Bilateral & Prednisone, CSA & Prednisone & no \\
\hline 17 & Pars Planitis & Intermediate & Bilateral & Prednisone, AZA, CSA & CSA & no \\
\hline 18 & Sarcoidosis & Panuveitis & Bilateral & Prednisone, AZA & Prednisone & no \\
\hline
\end{tabular}

\subsection{Data Collection}

The aim of the study was to evaluate the control of ocular inflammation and to observe choroidal and retinal changes after anti-TNF $\alpha$ injection. Anterior chamber cells, anterior chamber flare, and vitreous haze were evaluated and graded according to SUN criteria [36]. Parameters acquired included demographic information (age, gender), medical history, duration of follow-up, uveitis aetiology, previous and concomitant immunosuppressive drugs, date of the first injection, and adverse events. All the parameters were collected at baseline, after 3 months (3M), 6 months $(6 \mathrm{M})$, 9 months (9M), 12 months (12M), and, in some cases, over 12 months (>12M).

\subsection{Adalimumab Administration}

A complete physical evaluation and laboratory tests (complete blood cell count, serum protein electrophoresis, transaminases, hepatitis serology, C-reactive protein (CRP), QuantiFERON-TB-Gold ${ }^{\circledR}$, antinuclear antibodies) and chest X-rays were performed before the beginning of Anti-TNF therapy to exclude hepatic toxicity or the presence of an infectious uveitis aetiology. Serological tests were repeated every three months in order to prevent Adalimumab's adverse events. Adalimumab was administered as one subcutaneous injection ( $40 \mathrm{mg}$ ) every 2 weeks after an initial dose of $80 \mathrm{mg}$.

\subsection{Ophthalmic Examination}

All patients underwent a complete slit lamp examination with evaluation of the fundus, LogMar (Logarithm of the Minimum Angle of Resolution) Best Corrected Visual Acuity (BCVA) assessment 
and Intra-Ocular Pressure (IOP) measurements with applanation tonometry. OCT scans were collected with the Heidelberg Spectralis system (Heidelberg Engineering, Heidelberg, Germany) using the "Follow-up" function. This function allows the automatic detection of previous scans location, which are then used by the software to make subsequent image acquisitions. Macular and choroidal subfoveal thickness (micron) measurements were collected using the same scan at all follow-up visits. Fluorescein angiography (Heidelberg Retina Angiograph 2 (HRA2); Heidelberg Engineering, Heidelberg, Germany) and Indocyanine Green Angiography were performed in order to assess the presence of vasculitis, inflammatory choroidal neovascularization, or papilledema at baseline and at $12 \mathrm{M}$ and during the follow-up in accordance with an ophthalmological examination.

\subsection{Statistical Analysis}

Statistical analysis was performed using Statistical Package for Social Sciences (SPSS, version 22.0, IBM, Armonk, NY, USA). One eye for each patient was randomly chosen using the "Select Cases" function on SPSS. Qualitative variables were expressed as frequencies and percentages; quantitative variables were expressed using mean and standard deviation (SD). Median and IQR (interquartile ranges) were used to describe vasculitis (number of quadrants) and macular and choroidal thickness (micron). The Friedman test was used for multiple dependent comparisons with the post-hoc Wilcoxon signed rank test; Bonferroni adjustment was applied. A $p$-value $\leq 0.01$ was considered statistically significant.

\subsection{Efficacy Objectives}

The primary objective was the control of ocular inflammation, defined by a lack of anterior chamber and vitreous cells, adhering to the SUN criteria, and a reduction of macular edema. The secondary objectives included the full analysis of the evolution of the mean macular thickness (MMT) and subfoveal choroidal thickness (SCT) in the central $1 \mathrm{~mm}$ area, measured using optical coherence tomography (OCT) (HRA 2-KT, Heidelberg Engineering, Heidelberg, Germany), the presence of vasculitis, neovascularizations or papilledema confirmed by indocyanine green angiography and fluorescein angiography (HRA 2, Heidelberg Engineering, Heidelberg, Germany). Moreover, changes in visual acuity and changes in other systemic or local treatments, including corticosteroid withdrawal, and modifications of retinal architecture were described.

\section{Results}

A total of 18 patients (18 eyes) were analysed. The mean age was $39 \pm 13.40$ years; 14 patients $(78 \%)$ were males and four patients $(22 \%)$ were females. The medium follow-up period was $22 \pm 8$ months (Minimum 12; Maximum 34).

Uveitis was bilateral in $99.44 \%$ of cases. Two patients had uveitis secondary to psoriatic arthritis (11.11\%); 10 patients were affected by Behçet disease (55\%) and three of them showed an overlapping syndrome (30\%); three patients presented with pars planitis $(16.66 \%)$; three patients had other forms of ocular inflammation (Table 1).

\subsection{Inflammation Control}

Fifteen patients ( $83.3 \%$ ) presented successful inflammation control; at the final follow-up, there was lack of inflammatory activity according to SUN criteria (Table 2) or a reduction of inflammatory activity according to SUN criteria and reduction of the inflammation at the posterior pole (macular edema and vasculitis reduction). In fact, seven patients (38.9\%) had a reduction in anterior chamber flare, eight patients (44.4\%) of anterior chamber cells, and eight (44.4\%) of vitreous haze. 
Table 2. Patient evaluation according to SUN Criteria.

\begin{tabular}{ccccccc}
\hline Anterior Chamber Flare & $\mathbf{1 +}$ & $\mathbf{2 +}$ & $\mathbf{3 +}$ & $\mathbf{4 +}$ & \\
\hline M0 & $\begin{array}{c}\text { Patients } \\
(n=8)\end{array}$ & 7 & 1 & - & - & \\
$\mathbf{M} 12$ & $\begin{array}{c}\text { Patients } \\
(n=1)\end{array}$ & 1 & - & - & - & \\
\hline Anterior Chamber Cells & $\mathbf{0 . 5 +}$ & $\mathbf{1 +}$ & $\mathbf{2 +}$ & $\mathbf{3 +}$ & $\mathbf{4 +}$ \\
\hline M0 & $\begin{array}{c}\text { Patients } \\
(n=8)\end{array}$ & 3 & 4 & 1 & - & - \\
M12 & $\begin{array}{c}\text { Patients } \\
(n=1)\end{array}$ & 1 & - & - & - & - \\
\hline Vitreous Haze & $\begin{array}{c}\text { Patients } \\
(n=9) \\
\text { Matients } \\
(n=4)\end{array}$ & 1 & $\mathbf{2}$ & $\mathbf{3}$ & $\mathbf{4}$ & $\mathbf{5}$ \\
\hline M12 & 3 & 4 & 4 & - & - \\
\hline
\end{tabular}

Three patients (16.7\%) did not reach the primary endpoint: two patients had side effects which led to therapy discontinuation (one of them having worsening of vitreous haze according to SUN criteria) and another patient did not show complete absence of intraocular inflammation. Despite a reduction in vitreous haze grade, according to SUN criteria, macular edema was still present.

In accordance with SUN definitions [36], inactive uveitis was achieved in 14 patients, and an improvement in uveitis could be seen in one additional patient.

\subsection{Changes in Macular Thickness and Visual Acuity}

A progressive decrease in macular thickness was observed after the initiation of the anti-TNF- $\alpha$ therapy from a median of $229.75 \mu \mathrm{m}$ at M0 to $212.75 \mu \mathrm{m}$ at M3, $209.5 \mu \mathrm{m}$ at M6, and 213 $\mu \mathrm{m}$ at M12, i.e., a $7.29 \%$ reduction in the sample and $15.47 \%$ in the contralateral eye (Table 3 ). Furthermore, a significant increase in the mean best corrected visual acuity (log MAR) was observed after initiation of the anti-TNF- $\alpha$ therapy, with an improvement from $0.51 \pm 0.6$ at M0 to $0.24 \pm 0.5$ at $\mathrm{M}$ $>12$ (Table 4 ), with a $p$-value of 0.01 .

Table 3. Macular thickness, choroidal thickness, and vasculitis at each evaluation.

\begin{tabular}{|c|c|c|c|c|c|c|}
\hline & M0 & M3 & M6 & M9 & M12 & $M>12$ \\
\hline $\begin{array}{l}\text { Choroidal Thickness } \\
\text { (micron)-Median }\end{array}$ & 236.0 & 223.5 & 208.75 & 223.5 & 208.75 & 208.75 \\
\hline \multirow{2}{*}{ IQR } & 260 & 263.0 & 257.5 & 251.5 & 236.5 & 238.5 \\
\hline & 302 & 338.75 & 305.75 & 296 & 286.25 & 288.5 \\
\hline Friedman Test & \multicolumn{6}{|c|}{0.07} \\
\hline $\begin{array}{l}p \text {-value between baseline and } \\
\text { last follow-up visit } \\
\text { (Wilcoxon signed-rank test) }\end{array}$ & \multicolumn{6}{|c|}{0.01} \\
\hline $\begin{array}{l}\text { Macular Thickness } \\
\text { (micron)-Median }\end{array}$ & 229.75 & 212.75 & 209.5 & 218.75 & 213 & 197.25 \\
\hline \multirow{2}{*}{ IQR } & 247 & 234.5 & 236 & 238 & 239.5 & 239.5 \\
\hline & 389 & 279 & 284.75 & 286.75 & 279.5 & 279.5 \\
\hline Friedman Test & \multicolumn{6}{|c|}{0.35} \\
\hline $\begin{array}{c}p \text {-value between baseline and } \\
\text { last follow-up visit } \\
\text { (Wilcoxon signed-rank test) }\end{array}$ & \multicolumn{6}{|c|}{0.07} \\
\hline
\end{tabular}


Table 3. Cont.

\begin{tabular}{|c|c|c|c|c|c|c|}
\hline & M0 & M3 & M6 & M9 & M12 & $M>12$ \\
\hline $\begin{array}{l}\text { Vasculitis (Number of } \\
\text { Quadrants)-Median }\end{array}$ & 0 & 0 & 0 & 0 & 0 & 0 \\
\hline & 0 & 0 & 0 & 0 & 0 & 0 \\
\hline IQR & 4 & 1.75 & 1 & 1 & 0.75 & 0 \\
\hline Friedman Test & \multicolumn{6}{|c|}{$<0.001$} \\
\hline $\begin{array}{l}p \text {-value between baseline and } \\
\text { other evaluations } \\
\text { (Wilcoxon signed-rank test with } \\
\text { Bonferroni adjustment) }\end{array}$ & & 0.04 & 0.01 & 0.01 & 0.01 & 0.01 \\
\hline
\end{tabular}

Table 4. Sample features.

\begin{tabular}{ccc}
\hline & M0 & M > 12 \\
\hline BCVA (LogMAR) & & \\
Mean & 0.51 & 0.24 \\
Standard Deviation & 0.6 & 0.5 \\
\hline ERM & & \\
Number & 4 & 5 \\
Percentage & 22.22 & 27.78 \\
\hline Spots & & \\
Number & 4 & 2 \\
Percentage & 22.22 & 11.11 \\
\hline Papillitis & & \\
Number & 4 & 2 \\
Percentage & 22.22 & 11.11 \\
\hline Vitritis & & \\
Number & 9 & 4 \\
Percentage & 50.00 & 22.22 \\
\hline
\end{tabular}

BCVA: Best Corrected Visual Acuity; LogMar: Logarithm of Minimum Angle of Resolution.

\subsection{Changes in Choroidal Thickness}

A progressive decrease in choroidal thickness was observed after the initiation of the anti-TNF- $\alpha$ therapy from a median of $236.0 \mu \mathrm{m}$ at $\mathrm{M} 0$ to $223.5 \mu \mathrm{m}$ at M3, $208.75 \mu \mathrm{m}$ at M6, and $208.75 \mu \mathrm{m}$ at M12, i.e., an $11.54 \%$ reduction (Table 3). Choroidal folds could be seen in one patient at baseline and significantly reduced at M3 (Figure 1). 


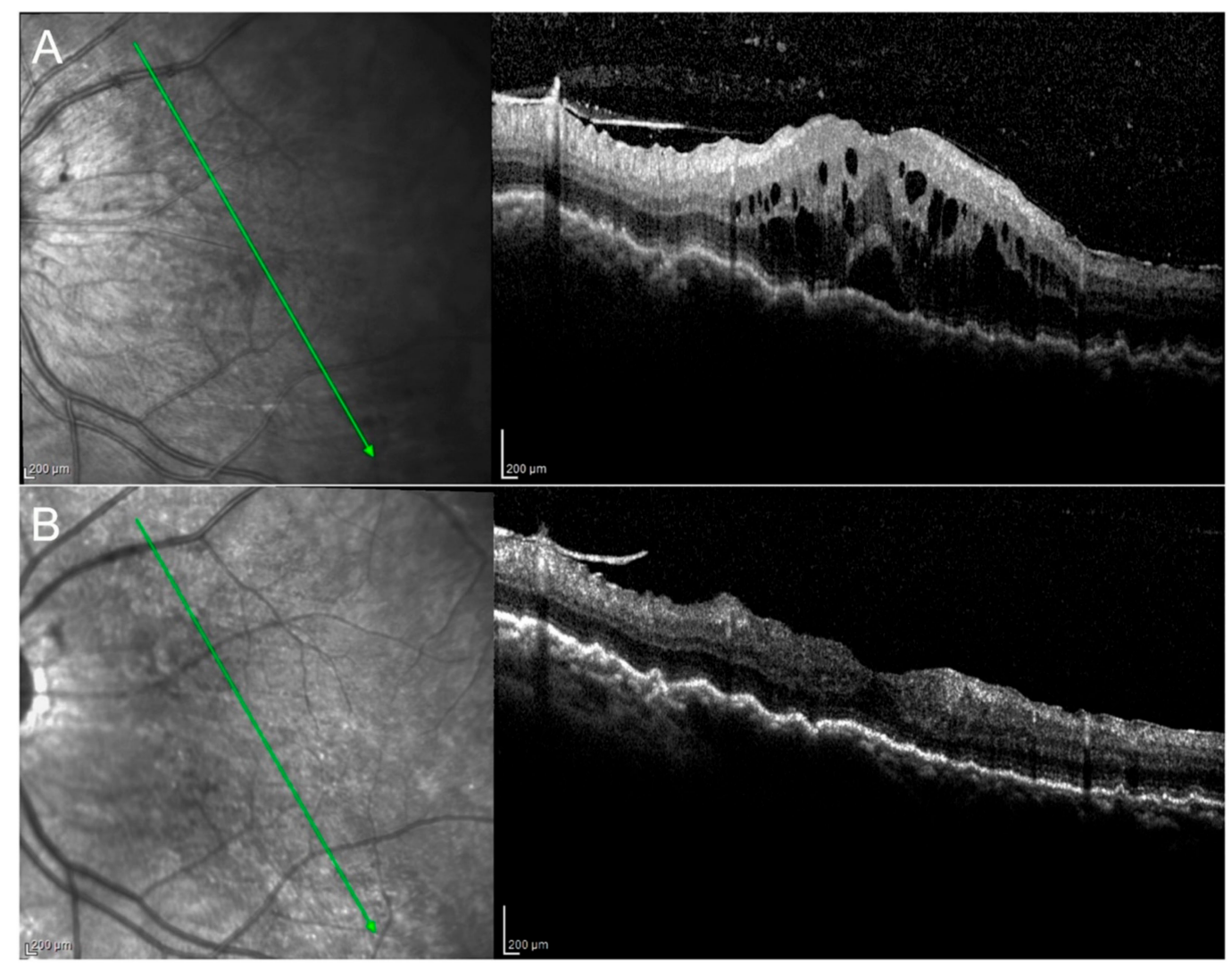

Figure 1. Birdshot retinopathy. Picture at baseline (A) shows the presence of macular edema and choroidal folds, which decreased at M3 (B). Vitritis (A) resolved at M3 (B).

Results of the ophthalmic examination, OCT, and FA (presence of epiretinal membrane, retinal hyperreflective spots, papillitis, vitritis) are summarized in Table 4, and some selected examples can be seen in Figures 2-4.

Granulomas were described at M0 in the patient affected by sarcoidosis and disappeared at M3. There was a significant reduction of vasculitis (number of quadrants affected) from M0 to M $>12$ with a $p$-value of 0.01 (Table 3; Figure 3). 


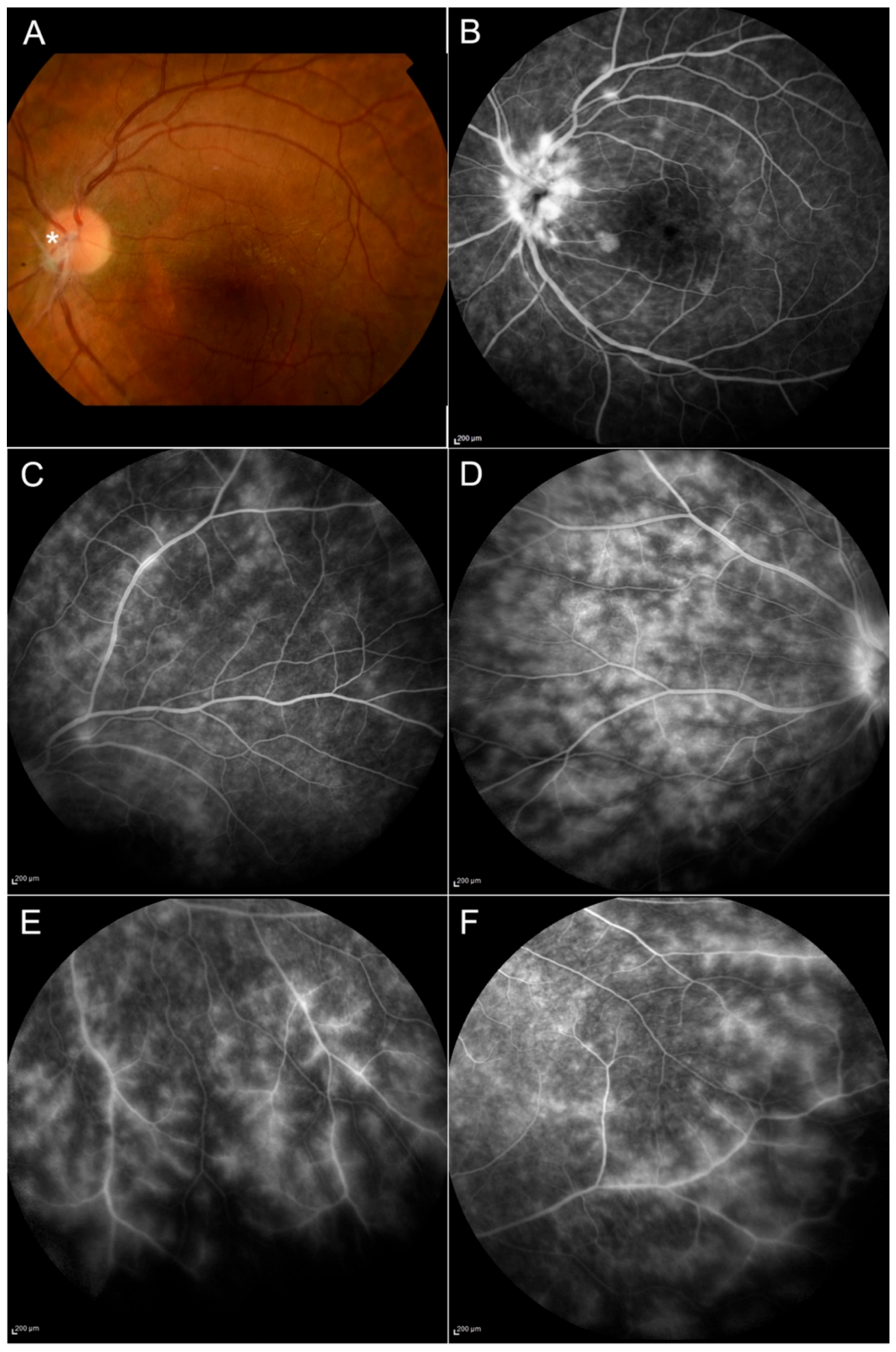

Figure 2. Behçet disease. Signs of active vasculitis can be seen in the posterior pole $(\mathbf{A}, \mathbf{B})$ and in the peripheral retina (C-F) with the presence of ischemic areas; papillitis is shown in (B). The fundus image displays the presence of hyalinized retinal vessels (asterisk) and an epiretinal membrane on the macula (A). 


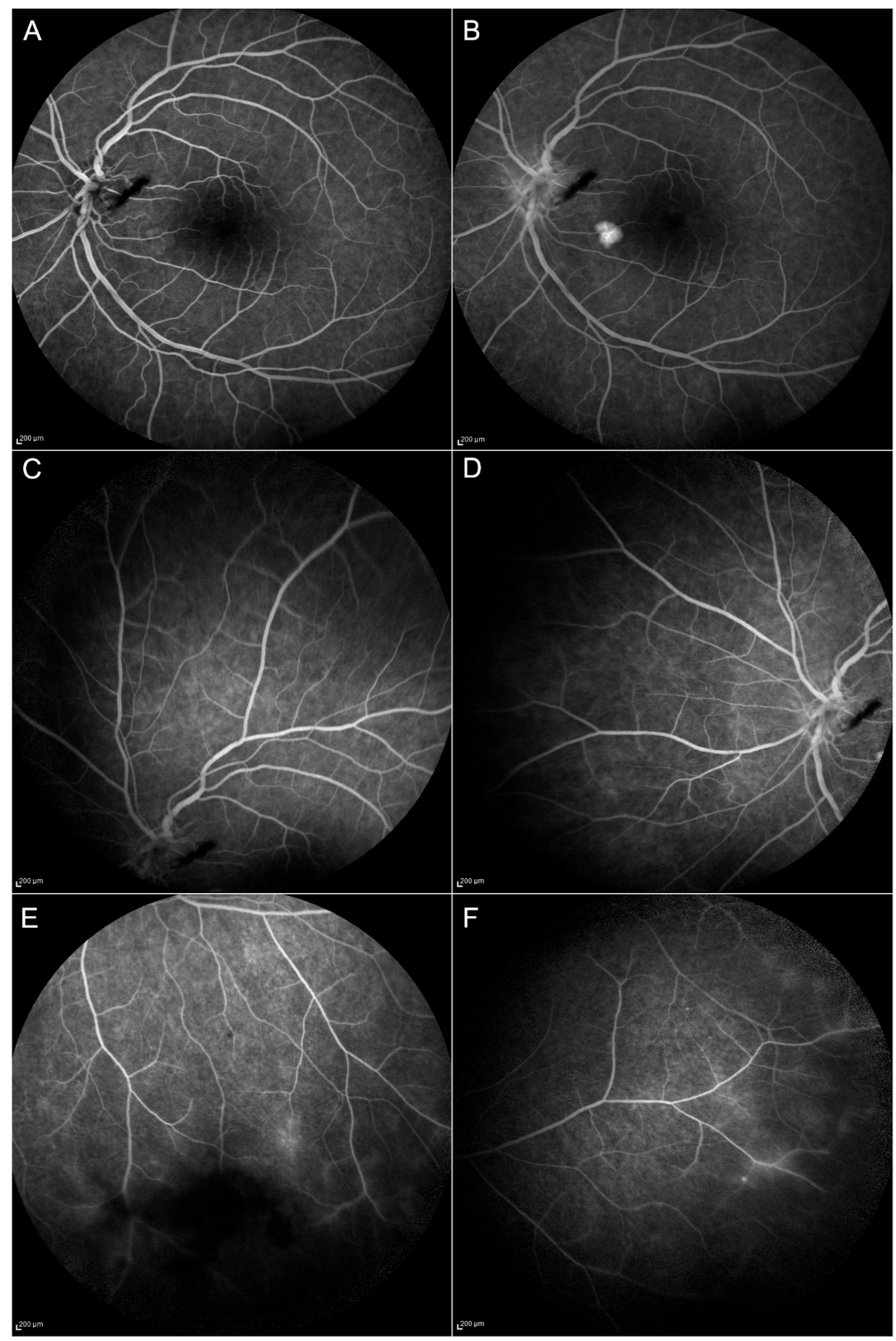

Figure 3. Follow-up at month 12 (M12) of the patient shown in Figure 2. Blood-retinal barrier alterations are still evident at the posterior pole from the early (A) to the late phases (B) of Fluorescein Angiography (FA). Peripheral vasculitis (C-F) and optic disc inflammation $(\mathbf{A}, \mathbf{B})$ are reduced compared to baseline but can still be appreciated in the inferior and the temporal sector of the peripheral retina ( $\mathbf{E}$ and $\mathbf{F}$, respectively). 


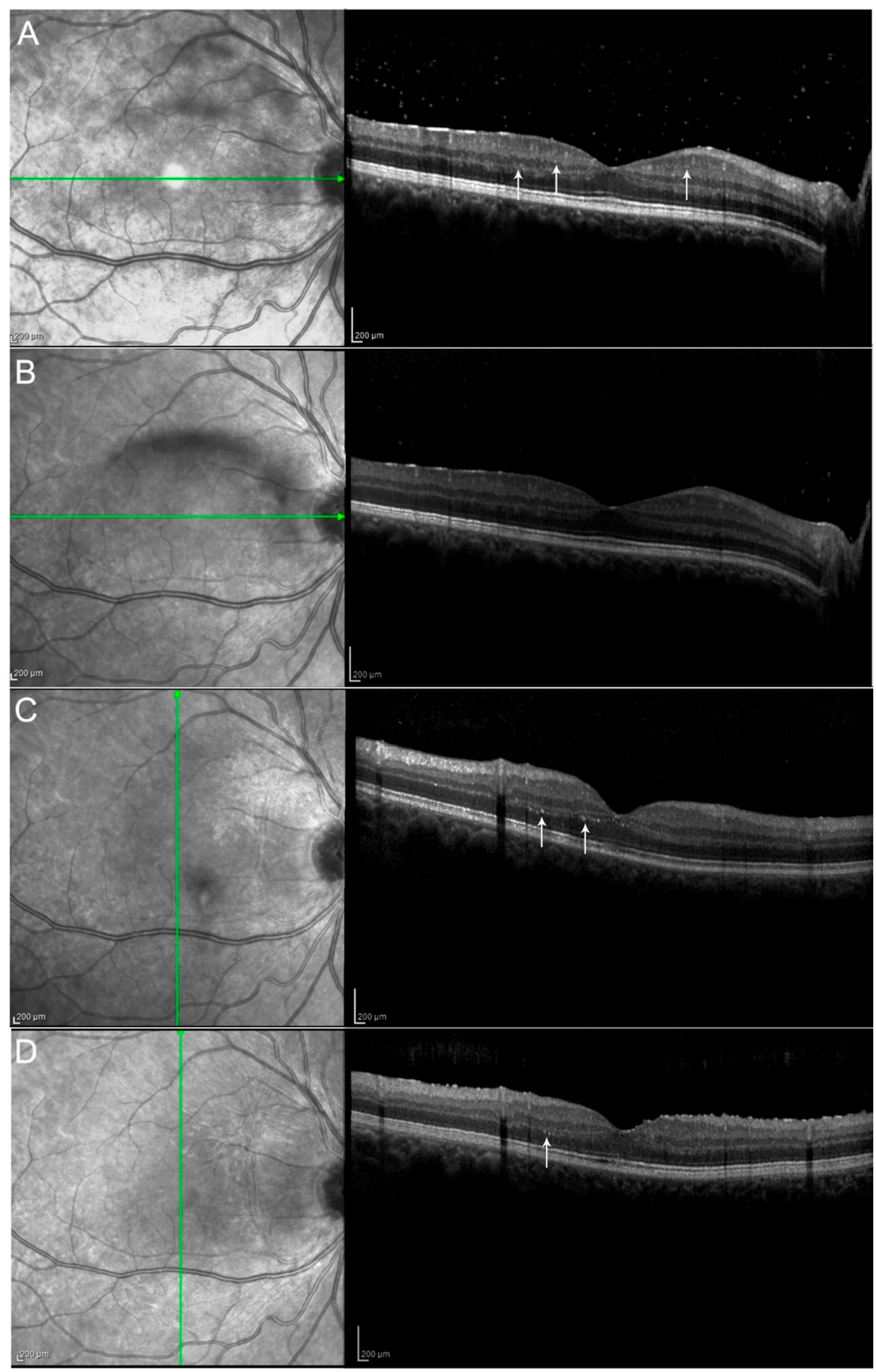

Figure 4. Hyperreflective retinal spots (see arrows) and vitritis shown at baseline (A) decreased one month after the beginning of the therapy with Adalimumab (B-D) show the same patient at M3 and M6 respectively with further improvement, although without complete disappearance of the spots. Hyperreflective spots have already been described as aggregates of activated microglial cells and could be considered a marker of neuroinflammatory response in the retina. They may also reflect retinal microvascular changes that occur in uveitic inflammation. 


\subsection{Changes in Systemic and Local Therapies}

Previous immunosuppressive treatments are summarized in Table 1. For most patients $(83.3 \%$, $n=15 / 18$ ) at M12, the systemic immunosuppressive therapy was reduced or completely discontinued with anti-TNF- $\alpha$ therapy. A total withdrawal of the corticosteroid therapy was obtained in $38.8 \%$ of patients $(n=7 / 18)$, four patients still received a daily dosage of prednisone over $10 \mathrm{mg}$ during anti-TNF- $\alpha$ therapy, and none had to increase the corticosteroid therapy. Regarding other immunosuppressive treatments, nine patients had methotrexate, cyclosporin A or azathioprine associated with the anti-TNF- $\alpha$ therapy at M12 (Table 1).

\subsection{Side Effects and Safety of the Anti-TNF- $\alpha$ Therapy}

A total of $11.1 \%$ of patients ( $n=2)$ experienced adverse events leading to treatment discontinuation: one patient reported diplopia which occurred after 14 months of anti-TNF- $\alpha$ therapy, while another had a worsening of vitreous inflammation and opacity after 15 months of treatment. Moreover, two patients complained of pain at the injection site with Adalimumab, while one patient reported erectile dysfunction.

\section{Discussion}

In this study, anti-TNF- $\alpha$ therapy with Adalimumab led to the effective and sustained control of ocular inflammation for $83.3 \%$ of patients at M12. According to SUN criteria anterior chamber flare, anterior chamber cells and vitreous haze grading decreased consistently.

Moreover, the anti-TNF- $\alpha$ therapy was effective in treating macular edema with a reduction of MMT at every follow-up visit. We observed a 7.29\% reduction in MMT at M12 in the study eye and a $15.47 \%$ in the fellow eye. This is consistent with the key role of TNF-alpha in the regulation of ocular levels of different chemokines, including VEGF, TGF-beta, angiotensin II, IL-1, IL-6, and IL-8, which drive the development of macular edema and choroidal neovascularization. In parallel, there was a clear and statistically significant improvement in BCVA due to the reduction of macular thickness and vitritis. This is a very important result for patients, since improved visual acuity helps with the achievement of a better quality of life.

Another aspect which might have played a beneficial role in this choice was the fact that therapeutic adherence was reported as very high, as taking an incorrect dose or taking the medication at the wrong times was very difficult to achieve.

Another important parameter evaluated in this study is the change in SCT after treatment: in fact, a significant reduction was found, with a median value that reached $208.75 \mu \mathrm{m}$ at $\mathrm{M}>12$ from baseline values of $236 \mu \mathrm{m}$. As choroidal circulation derives from systemic circulation, the eye might become a window through which to look at the whole organism, and to evaluate vascular modifications associated with systemic diseases [37].

During the active phase of the disease, the inflammatory vasodilation, first described by the Roman Cornelius Celsus, leads to an increase in choroidal thickness; this phenomenon, associated with an alteration in the outer blood-retinal barrier, may also explain the increase in macular thickness, due to a macula hyperhydration, also in absence of an evident macular edema [38].

Moreover, retinal circulation (which shares an embryological origin with cerebral circulation) must also be evaluated in these patients; in case of vascular retinal abnormalities, a thorough examination of the central nervous system must be performed with contrast-enhanced magnetic resonance imaging.

On fluorescein angiography, features of papillitis were found in four eyes at M0 and two eyes of one patient at the last follow-up visit, due to a chronic alteration of the outer blood-retina barrier.

There was a significant reduction in vasculitis over the four retinal quadrants from $\mathrm{M} 0$ to $\mathrm{M}>12$ with a $p$-value of 0.01 and between the baseline and the other follow-up periods (Table 3 ). 
Using optical coherence tomography, an inflammatory epiretinal membrane could be assessed in four eyes (22.22\%) at M0; therefore, the observed decrease in MMT, caused by anti-TNF- $\alpha$ therapy with Adalimumab, might have been underestimated because of macular traction.

Neuroinflammation in the retinal layers has already been described in different diseases such as diabetes, retinal vein occlusion, and age-related macular degeneration [39-41]; these hyperreflective spots were interpreted as a microglial response to inflammation and to date, they have not been previously reported in these uveitic conditions and might be considered a sign of disease activity (Figure 3).

The withdrawal of systemic corticosteroids represents another critical need, because even though the control of the ocular inflammation can be obtained with low doses of prednisone, adverse side effects persist in the long term. In our study, a complete corticosteroid withdrawal with anti-TNF- $\alpha$ therapy was obtained in $38.8 \%$ of patients.

Anti-Adalimumab antibody formation with subsequent reduction of the response in patients treated with Adalimumab has been reported [42]; therefore, the addition of another immunomodulatory drug to anti-TNF monotherapy can reduce antibody formation and produce a synergic effect with Adalimumab, blocking different inflammatory pathways, even at a suboptimal dosage $[43,44]$.

Moreover, in our Behçet patients, we chose not to add cyclosporine as an adjunctive immunomodulatory therapy as it seems to be associated with an increased risk of neurological involvement [45].

Anti-TNF- $\alpha$ may potentially induce severe side effects, including viral and bacterial infections, severe anaphylactic reactions, demyelinating neurological disorders, and the development of tumors (especially lymphoma).

In our study, $11.1 \%$ of patients $(n=2)$ experienced adverse events leading to treatment discontinuation; similarly, Adalimumab therapy was stopped in $9.5 \%$ of patients $(n=2)$ in the study by Mercier AE et al. [3].

Moreover, this might be considered a good rate when compared with other studies evaluating other anti-TNF- $\alpha$ drugs in the treatment of uveitis (19.3\% of treatment discontinuation in the study performed by Kruh et al., and $19.4 \%$ in the study performed by Suhler et al.) [46,47].

In conclusion, the main limitations of this study are its retrospective nature and the fact that it is a single center study with a limited number of patients; however, our results showed the long-term effective control of Adalimumab in patients with noninfective uveitis, with preservation or even improvement in visual acuity.

Moreover, we report Adalimumab efficacy in reducing the hyperreflective retinal dots on optical coherence tomography (interpreted as a microglial response to inflammation, a sign of disease activity which, to date, has not been previously reported in these uveitic conditions).

An additional benefit was achieved in terms of ocular control and reduction of steroid dose and immunosuppressant drugs. Moreover, our data might help in the daily management of patients with noninfectious uveitis in a real-world setting.

\section{Conclusions}

Our study confirms the efficacy and safety of Adalimumab for the control of ocular inflammation in non-infectious uveitis and in particular when the uveitis is refractory to other therapy, including corticosteroids and immunosuppressive drugs. Moreover, additional data were given by means of multimodal imaging and may represent an opportunity for further research in this field. Visual acuity preservation and corticosteroids sparing represent additional benefits in the long-term management of these patients. For these reasons, it would be interesting to further investigate the efficacy of this anti-TNF- $\alpha$ therapy in large cohorts of patients affected by refractory non-infectious uveitis. 
Author Contributions: Conceptualization, V.P. and P.P. (Paolo Pelliccioni); Data curation, S.D.T., R.G.; Formal analysis, S.D.T., R.G.; Supervision, C.M.; Validation, M.N.; Writing-original draft, V.P., P.P. (Paolo Pelliccioni) and A.R.; Writing - review \& editing, A.F. and P.P. (Pierangelo Pasanisi). All authors have read and agreed to the published version of the manuscript.

Conflicts of Interest: The authors declare no conflict of interest.

\section{References}

1. Massa, H.; Pipis, S.Y.; Adewoyin, T.; Vergados, A.; Patra, S.; Panos, G.D. Macular Edema Associated with Non-Infectious Uveitis: Pathophysiology, Etiology, Prevalence, Impact and Management Challenges. Clin. Ophthalmol. 2019, 13, 1761-1777. [CrossRef] [PubMed]

2. Thorne, J.E.; Suhler, E.; Skup, M.; Tari, S.; Macaulay, D.; Chao, J.; Ganguli, A. Prevalence of Noninfectious Uveitis in the United States: A Claims-Based Analysis. JAMA Ophthalmol. 2016, 134, 1237-1245. [CrossRef] [PubMed]

3. Mercier, A.E.; Ribeiro, E.; Korobelnik, J.F.; Delyfer, M.N.; Rougier, M.B. Efficacy of Anti-TNF- $\alpha$ Therapy for the Treatment of Non-Infectious Uveitis: A Retrospective Study of 21 Patients. Ocul. Immunol. Inflamm. 2018, 26, 477-484. [CrossRef] [PubMed]

4. Fardeau, C.; Champion, E.; Massamba, N.; Lehoang, P. Uveitic Macular Edema. Eye 2016, 30, 1277-1292. [CrossRef] [PubMed]

5. Gritz, D.C.; Wong, I.G. Incidence and Prevalence of Uveitis in Northern California: The Northern California Epidemiology of Uveitis Study. Ophthalmology 2004, 111, 491-500. [CrossRef]

6. Suhler, E.B.; Lloyd, M.J.; Choi, D.; Rosenbaum, J.T.; Austin, D.F. Incidence and Prevalence of Uveitis in Veterans Affairs Medical Centers of the Pacific Northwest. Am. J. Ophthalmol. 2008, 146, 890-896. [CrossRef]

7. Tallouzi, M.O.; Moore, D.J.; Calvert, M.; Murray, P.I.; Bucknall, N.; Denniston, A.K. The Effectiveness of Pharmacological Agents for the Treatment of Uveitic Macular Oedema (UMO): A Systematic Review Protocol. Syst. Rev. 2016, 5, 29. [CrossRef]

8. Abdulaal, M.R.; Abiad, B.H.; Hamam, R.N. Uveitis in the Aging Eye: Incidence, Patterns, and Differential Diagnosis. J. Ophthalmol. 2015, 2015, 509456. [CrossRef]

9. Rao, N. Uveitis in Developing Countries. Indian J. Ophthalmol. 2013, 61, 253-254. [CrossRef]

10. Lardenoye, C.W.T.A.; van Kooij, B.; Rothova, A. Impact of Macular Edema on Visual Acuity in Uveitis. Ophthalmology 2006, 113, 1446-1449. [CrossRef]

11. Durrani, O.M.; Meads, C.A.; Murray, P.I. Uveitis: A Potentially Blinding Disease. Ophthalmologica 2004, 218, 223-236. [CrossRef] [PubMed]

12. Kaiser, P.K. Prospective Evaluation of Visual Acuity Assessment: A Comparison of Snellen versus ETDRS Charts in Clinical Practice (an Aos Thesis). Trans. Am. Ophthalmol. Soc. 2009, 107, 311-324. [PubMed]

13. Rothova, A.; Suttorp-van Schulten, M.S.A.; Frits Treffers, W.; Kijlstra, A. Causes and Frequency of Blindness in Patients with Intraocular Inflammatory Disease. Br. J. Ophthalmol. 1996, 80, 332-336. [CrossRef] [PubMed]

14. Koronis, S.; Stavrakas, P.; Balidis, M.; Kozeis, N.; Tranos, P.G. Update in Treatment of Uveitic Macular Edema. Drug Des. Dev. Ther. 2019, 13, 667-680. [CrossRef] [PubMed]

15. Valentincic, N.V.; de Groot-Mijnes, J.D.F.; Kraut, A.; Korosec, P.; Hawlina, M.; Rothova, A. Intraocular and Serum Cytokine Profiles in Patients with Intermediate Uveitis. Mol. Vis. 2011, 17, 2003-2010.

16. Omri, S.; Behar-Cohen, F.; De Kozak, Y.; Sennlaub, F.; Mafra Verissimo, L.; Jonet, L.; Savoldelli, M.; Omri, B.; Crisanti, P. Microglia/Macrophages Migrate through Retinal Epithelium Barrier by a Transcellular Route

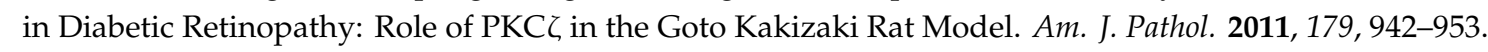
[CrossRef]

17. Pohlmann, D.; Macedo, S.; Stübiger, N.; Pleyer, U.; Joussen, A.M.; Winterhalter, S. Multimodal Imaging in Birdshot Retinochoroiditis. Ocul. Immunol. Inflamm. 2017, 25, 621-632. [CrossRef]

18. Herbort, C.P.; LeHoang, P.; Guex-Crosier, Y. Schematic Interpretation of Indocyanine Green Angiography in Posterior Uveitis Using a Standard Angiographic Protocol. Ophthalmology 1998, 105, 432-440. [CrossRef]

19. Giuliari, G.; Hinkle, D.M.; Foster, C.S. The Spectrum of Fundus Autofluorescence Findings in Birdshot Chorioretinopathy. J. Ophthalmol. 2009, 2009, 567693. [CrossRef]

20. Davis, J. Current Concepts in the Management of Uveitic Macular Edema. Johns Hopkins Adv. Stud. Ophthalmol. 2010, 30, 138-150. 
21. Jabs, D.A.; Rosenbaum, J.T.; Foster, C.S.; Holland, G.N.; Jaffe, G.J.; Louie, J.S.; Nussenblatt, R.B.; Stiehm, E.R.; Tessler, H.; Van Gelder, R.N.; et al. Guidelines for the Use of Immunosuppressive Drugs in Patients with Ocular Inflammatory Disorders: Recommendations of an Expert Panel. Am. J. Ophthalmol. 2000, 130, 492-513. [CrossRef]

22. Kok, H.; Lau, C.; Maycock, N.; McCluskey, P.; Lightman, S. Outcome of Intravitreal Triamcinolone in Uveitis. Ophthalmology 2005, 112, 1916.e1-1916.e7. [CrossRef] [PubMed]

23. Venkatesh, P.; Kumar, C.S.; Abbas, Z.; Garg, S. Comparison of the Efficacy and Safety of Different Methods of Posterior Subtenon Injection. Ocul. Immunol. Inflamm. 2008, 16, 217-223. [CrossRef] [PubMed]

24. McCluskey, P.J.; Towler, H.M.A.; Lightman, S. Regular Review: Management of Chronic Uveitis. Br. Med. J. 2000, 102, 733-742. [CrossRef]

25. Menezo, V.; Lau, C.; Comer, M.; Lightman, S. Clinical Outcome of Chronic Immunosuppression in Patients with Non-Infectious Uveitis. Clin. Exp. Ophthalmol. 2005, 33, 16-21. [CrossRef]

26. Deuter, C.M.E.; Kötter, I.; Günaydin, I.; Stübiger, N.; Doycheva, D.G.; Zierhut, M. Efficacy and Tolerability of Interferon Alpha Treatment in Patients with Chronic Cystoid Macular Oedema Due to Non-Infectious Uveitis. Br. J. Ophthalmol. 2009, 93, 906-913. [CrossRef]

27. Neri, P.; Mariotti, C.; Cimino, L.; Mercanti, L.; Giovannini, A. Long-Term Control of Cystoid Macular Oedema in Noninfectious Uveitis with Mycophenolate Mofetil. Int. Ophthalmol. 2009, 29, 127-133. [CrossRef]

28. Artornsombudh, P.; Gevorgyan, O.; Payal, A.; Siddique, S.S.; Foster, C.S. Infliximab Treatment of Patients with Birdshot Retinochoroidopathy. Ophthalmology 2013, 120, 588-592. [CrossRef]

29. LeHoang, P.; Cassoux, N.; George, F.; Kullmann, N.; Kazatchkine, M.D. Intravenous Immunoglobulin (IVIg) for the Treatment of Birdshot Retinochoroidopathy. Ocul. Immunol. Inflamm. 2000, 8, 49-57. [CrossRef]

30. Steeples, L.R.; Spry, P.; Lee, R.W.J.; Carreño, E. Adalimumab in Refractory Cystoid Macular Edema Associated with Birdshot Chorioretinopathy. Int. Ophthalmol. 2018, 38, 1357-1362. [CrossRef] [PubMed]

31. Balevic, S.J.; Rabinovich, C.E. Profile of Adalimumab and Its Potential in the Treatment of Uveitis. Drug Des. Dev. Ther. 2016, 10, 2997-3003. [CrossRef]

32. Nguyen, Q.D.; Merrill, P.T.; Jaffe, G.J.; Dick, A.D.; Kurup, S.K.; Sheppard, J.; Schlaen, A.; Pavesio, C.; Cimino, L.; Van Calster, J.; et al. Adalimumab for Prevention of Uveitic Flare in Patients with Inactive Non-Infectious Uveitis Controlled by Corticosteroids (VISUAL II): A Multicentre, Double-Masked, Randomised, Placebo-Controlled Phase 3 Trial. Lancet 2016, 388, 1183-1192. [CrossRef]

33. Sheppard, J.; Joshi, A.; Betts, K.A.; Hudgens, S.; Tari, S.; Chen, N.; Skup, M.; Dick, A.D. Effect of Adalimumab on Visual Functioning in Patients with Noninfectious Intermediate Uveitis, Posterior Uveitis, and Panuveitis in the VISUAL-1 and VISUAL-2 Trials. JAMA Ophthalmol. 2017, 135, 511-518. [CrossRef] [PubMed]

34. Suhler, E.B.; Adán, A.; Brézin, A.P.; Fortin, E.; Goto, H.; Jaffe, G.J.; Kaburaki, T.; Kramer, M.; Lim, L.L.; Muccioli, C.; et al. Safety and Efficacy of Adalimumab in Patients with Noninfectious Uveitis in an Ongoing Open-Label Study: VISUAL III. Ophthalmology 2018, 125, 1075-1087. [CrossRef] [PubMed]

35. Jaffe, G.J.; Dick, A.D.; Brézin, A.P.; Nguyen, Q.D.; Thorne, J.E.; Kestelyn, P.; Barisani-Asenbauer, T.; Franco, P.; Heiligenhaus, A.; Scales, D.; et al. Adalimumab in Patients with Active Noninfectious Uveitis. N. Engl. J. Med. 2016, 375, 932-943. [CrossRef] [PubMed]

36. Jabs, D.A.; Nussenblatt, R.B.; Rosenbaum, J.T.; Atmaca, L.S.; Becker, M.D.; Brezin, A.P.; Chee, S.P.; Davis, J.L.; Deschenes, J.; de Smet, M.; et al. Standardization of Uveitis Nomenclature for Reporting Clinical Data. Results of the First International Workshop. Am. J. Ophthalmol. 2005, 140, 509-516. [CrossRef] [PubMed]

37. Pirani, V.; Pelliccioni, P.; De Turris, S.; Rosati, A.; Franceschi, A.; Cesari, C.; Nicolai, M.; Mariotti, C. The Eye as a Window to Systemic Infectious Diseases: Old Enemies, New Imaging. J. Clin. Med. 2019, 8. [CrossRef]

38. Kim, M.; Kim, H.; Kwon, H.J.; Kim, S.S.; Koh, H.J.; Lee, S.C. Choroidal Thickness in Behcet's Uveitis: An Enhanced Depth Imaging-Optical Coherence Tomography and Its Association with Angiographic Changes. Investig. Ophthalmol. Vis. Sci. 2013, 54, 6033-6039. [CrossRef]

39. Vujosevic, S.; Berton, M.; Bini, S.; Casciano, M.; Cavarzeran, F.; Midena, E. Hyperreflective Retinal Spots and Visual Function after Anti-Vascular Endothelial Growth Factor Treatment in Center-Involving Diabetic Macular Edema. Retina 2016, 36, 1298-1308. [CrossRef]

40. Vujosevic, S.; Torresin, T.; Bini, S.; Convento, E.; Pilotto, E.; Parrozzani, R.; Midena, E. Imaging Retinal Inflammatory Biomarkers after Intravitreal Steroid and Anti-VEGF Treatment in Diabetic Macular Oedema. Acta Ophthalmol. 2017, 95, 464-471. [CrossRef] 
41. Turgut, B.; Yildirim, H. The Causes of Hyperreflective Dots in Optical Coherence Tomography Excluding Diabetic Macular Edema and Retinal Venous Occlusion§§. Open Ophthalmol. J. 2015, 9, 36-40. [CrossRef] [PubMed]

42. Baert, F.; Kondragunta, V.; Lockton, S.; Casteele, N.V.; Hauenstein, S.; Singh, S.; Karmiris, K.; Ferrante, M.; Gils, A.; Vermeire, S. Antibodies to Adalimumab Are Associated with Future Inflammation in Crohnis Patients Receivingmaintenance Adalimumab Therapy: A Post Hoc Analysis of the Karmiris Trial. Gut 2016, 65, 1126-1131. [CrossRef] [PubMed]

43. Strik, A.S.; van den Brink, G.R.; Ponsioen, C.; Mathot, R.; Löwenberg, M.; D'Haens, G.R. Suppression of Anti-Drug Antibodies to Infliximab or Adalimumab with the Addition of an Immunomodulator in Patients with Inflammatory Bowel Disease. Aliment. Pharmacol. Ther. 2017, 45, 1128-1134. [CrossRef] [PubMed]

44. Ungar, B.; Kopylov, U.; Engel, T.; Yavzori, M.; Fudim, E.; Picard, O.; Lang, A.; Williet, N.; Paul, S.; Chowers, Y.; et al. Addition of an Immunomodulator Can Reverse Antibody Formation and Loss of Response in Patients Treated with Adalimumab. Aliment. Pharmacol. Ther. 2017, 45, 276-282. [CrossRef]

45. Akmar-Demir, G.; Ayranci, O.; Kurtuncu, M.; Vanli, E.N.; Mutlu, M.; Tugal-Tutkun, I. Cyclosporine for Behçet's Uveitis: Is It Associated with an Increased Risk of Neurological Involvement? Clin. Exp. Rheumatol. 2008, 26 (Suppl. 50), S84-S90.

46. Kruh, J.N.; Yang, P.; Suelves, A.M.; Foster, C.S. Infliximab for the Treatment of Refractory Noninfectious Uveitis: A Study of 88 Patients with Long-Term Follow-Up. Ophthalmology 2014, 121, 358-364. [CrossRef]

47. Suhler, E.B.; Smith, J.R.; Giles, T.R.; Lauer, A.K.; Wertheim, M.S.; Kurz, D.E.; Kurz, P.A.; Lim, L.; Mackensen, F.; Pickard, T.D.; et al. Infliximab Therapy for Refractory Uveitis: 2-Year Results of a Prospective Trial. Arch. Ophthalmol. 2009, 127, 819-822. [CrossRef]

(C) 2020 by the authors. Licensee MDPI, Basel, Switzerland. This article is an open access article distributed under the terms and conditions of the Creative Commons Attribution (CC BY) license (http://creativecommons.org/licenses/by/4.0/). 